Rhode Island College

Digital Commons @ RIC

Master's Theses, Dissertations, Graduate

Master's Theses, Dissertations, Graduate Research and Major Papers Overview

Research and Major Papers

2015

\title{
Visual Attention and Behavior Under Positive Stereotypes
}

Sathiarith Chau

Rhode Island College

Follow this and additional works at: https://digitalcommons.ric.edu/etd

Part of the Other Psychology Commons

\section{Recommended Citation}

Chau, Sathiarith, "Visual Attention and Behavior Under Positive Stereotypes" (2015). Master's Theses, Dissertations, Graduate Research and Major Papers Overview. 131.

https://digitalcommons.ric.edu/etd/131

This Thesis is brought to you for free and open access by the Master's Theses, Dissertations, Graduate Research and Major Papers at Digital Commons @ RIC. It has been accepted for inclusion in Master's Theses, Dissertations, Graduate Research and Major Papers Overview by an authorized administrator of Digital Commons @ RIC. For more information, please contact digitalcommons@ric.edu. 
VISUAL ATTENTION AND BEHAVIOR UNDER POSITIVE STEREOTYPES: OUTGROUP POSITIVITY BIAS OVERSHADOWS AFROCENTRICITY BIAS

\author{
by Sathiarith Chau
}

A Thesis Submitted in Partial Fulfillment of the Requirements of the Master of Arts in the Department of Psychology

Rhode Island College

2015

Abstract 
Afrocentricity bias occurs when Black individuals with dark skin, wide nose, and large lips are associated with certain negative and positive traits (e.g., criminality and athleticism) compared to those with Eurocentric features (i.e., light skin, narrow nose, thin lips). In racial bias research, inhibition of biased responses is common. The current study employed positive stereotypes associated with Blacks and Whites (physical and verbal ability, respectively) in order to link implicit behavior (visual attention) to explicit behavior. Participants selected, from an array of two faces, the best candidate for a team requiring either physical strength or verbal ability. Stereotypes did not affect visual behavior and choice; rather, Afrocentric features did. Visual attention to highly Afrocentric Black faces was greater when with White faces. In terms of choice, when present with two Black faces, the more Eurocentric face was more likely to be selected. Selections did not vary for White and highly Afrocentric Black candidate pairs. Eurocentric Black faces were selected more often when paired with a White candidate. Trait rating data showed that highly Afrocentric features resulted in higher ratings of agility and strength, whereas Eurocentric features resulted in higher ratings for verbal and grammatical skill. Although participants rated Blacks as predicted by Afrocentricity Bias, their behavior did not reflect the bias.

Keywords: positive stereotypes, Afrocentricity bias, out-group positivity bias

Table of Contents

I. Introduction $\quad 4$

$\begin{array}{lr}\text { II. Method } & 9\end{array}$

III. Results 14

$\begin{array}{lr}\text { IV. Discussion } & 20\end{array}$ 
V. Reference 26

$\begin{array}{llr}\text { VI. Appendix } & 28\end{array}$

\section{Visual Attention and Behavior under Positive Stereotypes: Out-Group Positivity Bias Overshadows Afrocentricity Bias}

In terms of physical differences between the self and a stranger, our attention focuses on categorical features that identify the person (Ostrom, Carpenter, Sedikides, \& Li, 1993). For instance, Black individuals are categorically defined by a combination of stereotypical or "Afrocentric" features; these are black skin tone, wide nose width, and broad lips (Maddox, 2004). Unlike in-group members, racially different out-group members inherently face more suspicion especially those with extreme racial features (Hagiwara, Kashy, \& Cesario, 2012). For instance, Afrocentric features have been shown to be associated with the ascription of traits and 
expected behaviors that are often negative (Maddox \& Gray, 2002; Eberhardt, Goff, Purdie, \& Davies, 2004). In addition, individuals that were considered Afrocentric "exemplars" (i.e., having facial characteristics at the extreme end of the spectrum) were more strongly associated with their negative stereotypes.

Prejudice towards the Black community by Whites has been shown to be more intricate than a mere dislike for someone with dark skin color. Research has shown that Whites are able to accurately encode the degree of tone (ranging from a light to dark) and use that information to construct subjective information about Blacks. For instance, in Maddox and Gray (2002), Whites were more likely to ascribe negative traits to male and female Blacks with dark skin tones in comparison to their light skin counterparts. In Blair, Judd, Sadler, and Jenkins (2002; Study 2), the same pattern of judgment was seen where faces with more extreme Afrocentric features were more likely to be matched with predefined descriptions that were negative and stereotypical compared to less Afrocentric faces. Wilkins, Kaiser, and Rieck (2010) also showed that Whites' accurate perception of the different skin toned Black targets influenced the way they subjectively determined the targets' level of racial identification (i.e., how close the Black individual would be to the Black community; dark targets were perceived to be more attached to their Black identity than light targets). Therefore, Whites are encoding the differences in facial features of Blacks.

Despite the attentiveness to the differences in Afrocentric features, the process has been shown to be primarily automatic in nature (Blair, Judd, \& Fallman, 2004b; Malloy, Chau, Bulevich \& Maddox, 2013). White perceivers are not explicitly aware of their discriminatory visual behavior. In Blair et al. (2004b), participants were instructed to read descriptive profiles (stereotypic or counter-stereotypic) and match them to the face stimuli (i.e., White, highly Afrocentric, and low Afrocentric male faces). Participants were also instructed to provide a confidence rating (0-99) when they matched a profile with a face. White participants were randomly assigned to the Afrocentric features suppression, racial features suppression, or no 
suppression condition. In the suppression groups, participants were instructed to avoid using either race or Afrocentric features as the basis for their matching criteria. Compared to the no suppression condition, there was a decrease in matching frequency and probability rating of stereotypical descriptions with Black faces for the race suppression condition. The same was true in the Afrocentric features suppression condition; however, the decrease was less pronounced. Most importantly, there was no significant difference between highly Afrocentric face and low Afrocentric faces in terms of the decline shown in the Afrocentricity suppression condition. The researchers explained that this finding suggested people are naïve to the idea of judging Black out-group members based on degrees of changes in facial features, but are attentive to stereotyping based on facial features that distinguished Black faces from White faces (Blair et al., 2004b; Study 3). Malloy et al. (2013) also showed that people are unable to suppress the bias in their visual behavior when viewing Black male faces in a crime situation. White participants were asked to find either the perpetrator or the victim of a crime using a lineup of three faces varying in skin tone (one feature defining Afrocentricity). This experimental context was used as the White participants were naturally primed to perceive dark skinned Blacks as more threatening than Whites and light skinned Blacks (Dixon \& Maddox, 2005). When visual attention was directly analyzed, dark toned faces were found to be frequently looked at more often and for longer durations compared to light toned faces under a negative prime ("find the perpetrator"). When participants were primed under a victim prime ("find the victim"), light toned faces attracted more attention than dark toned faces. Interestingly, however, when the participants were asked to actually select the faces that they believed were the perpetrators or victims, there was no significant bias for a particular tone. Visual attention was biased, yet behavior was not discriminatory.

The nature of the racial phenotype bias seems to be a powerful influence on people's behavior. In a criminal case review, inmates who were judged by participants to have a higher degree of Afrocentric features were on average incarcerated for longer periods of time despite having criminal history similar to inmates with less pronounced Afrocentric features (Blair, Judd, 
\& Chapleau, 2004a). The unbiased selections of perpetrators and victims in the Malloy et al (2013) study were therefore surprising as it did not match the predicted outcome which should reflect the finding of Blair et al. (2004a). This unexpected outcome may have been caused by the nature of the explicit choice of the crime target. In Blair et al. (2004b), participants had the flexibility of assigning probability ratings (0-99) to indicate the likelihood of the descriptions to the target face, whereas in Malloy et al. (2013) participants were asked to state which face was the crime target. Given the forced-choice format, this may have caused them to systematically avoid the dark toned faces to which they devoted more visual attention and randomly guess in an effort to consciously control discriminatory behavior.

One possibility that needs to be explored in order to address the discrepancy of Malloy et al. (2013) with other work should involve the use a more positive experimental context. There will be multiple changes to the methodology. The primary aims of the changes are to 1) increase ecological validity; 2) broaden visual attention to include the other Afrocentric features, nose and lips, along with skin tone; and 3) use positive group stereotypes in order to decrease the likelihood that Whites will consciously inhibit racial stereotypes as observed in Malloy et al. (2013).

In a majority of racial phenotypicality bias research, the stimuli used were predominantly digitally manipulated photographs of Black faces. In this study, the stimuli will also consist of more realistic photographs of faces. Despite having less control over the features of the photographed faces, the higher ecological validity will hopefully offset any error introduced through the use of artificial faces. The faces will also consist of Black males with manipulation of the three Afrocentric phenotypes (i.e. nose, lips, and skin tone).

There will also be a change in the nature of the task, which will hopefully be less likely to be recognized as a racial discrimination task. The paradigm will center on a task where members will be selected to become part of a certain type of work group (which will be a more covert way of assessing the racially associated stereotype). One group will require individuals with 
"physical strength and agility" while the other will require "verbal skill and proficient grammar". Unlike the previous eyewitness identification task in Malloy et al. (2013), the choices will be more positive in nature; faces will be selected based on a positive rather than a negative criterion. This change should still allow participants to form groups based on Afrocentric features but without their awareness. Research has shown that there are closely associated positive stereotypes that are connected to Blacks, with athleticism being a primary example (Eberhardt et al, 2004; Maddox, 2004; Blair et al, 2004b). Verbal skills will be the attribute more closely associated to Whites and potentially Black faces with less Afrocentric features (i.e., Eurocentric). The change should produce results more consistent with previous research on Afrocentric bias.

\section{Hypotheses}

Implicit (eye-tracking) and Explicit behavior (choice). The first set of predictions addresses how Afrocentricity affects unconscious visual behavior and deliberate actions (choice of the target team member).

Hypothesis 1:

Faces presented to participants will be all Black, all White or mixed race arrays of two people. Among participants forming work groups requiring verbal skill, for the all Black arrays, low Afrocentric faces will receive more visual attention and will be selected more than faces with high Afrocentric features. For mixed arrays, White faces will receive the most visual attention and will be selected for the verbal skill group, followed by low and then high Afrocentric faces.

Hypothesis 2:

For groups requiring physical skill, in the all Black arrays, high Afrocentric faces will receive more visual attention and will be selected more than faces with low Afrocentric faces. For mixed arrays, High Afrocentric faces will receive the most visual attention and choice, followed by Low Afrocentric faces and then White faces. 
Trait Judgments. The second set of predictions attempts to supplement previous research on how Afrocentricity affects trait judgments. Strength, agility, verbal, and grammatical ability were of primary interest as they are racial stereotypes.

Hypothesis 3:

High and Low Afrocentric faces will be rated higher than White faces when assessing physical strength and agility. In terms of the two Black faces, High Afrocentric faces will be rated higher than Low Afrocentric faces.

Hypothesis 4:

White faces will be rated higher than High and Low Afrocentric for verbal and grammatical ability. In terms of the two Black faces, Low Afrocentric faces would be rated higher than High Afrocentric faces.

\section{Method}

\section{Participants}

Sixty White participants (50\% female) were recruited from the psychology department participant pool of an urban university in New England. The mean age was 21.52 (SD = 3.38). Participants will be compensated with course credit and a stipend of $\$ 15$.

\section{Ethical Concerns}

The Rhode Island College Institutional Review Board have reviewed and approved this study. Participants completed an informed consent document when they arrive at the lab. They may terminate their participation at any time with no penalty. An alternative activity was 
provided for those who do not wish to participate in this experiment. Participants were debriefed about the deception used in the study after completion of the experiment.

\section{Design and Analyses}

Participants were assigned to the two different work group types (verbal vs. physical). Nested within group type will be the degree of Afrocentricity (high vs. low). Nested within degree of Afrocentricity were trials which consisted of 5 all Black arrays (2 faces per slide with 1 dark and 1 light Black face), 6 mixed arrays (in each array a Black face, either dark or light, was paired with a White face), and all White array (2 White faces). A mixed model ANOVA was used to analyze the behavioral (Eye-tracking behavior) and response data.

\section{Materials}

Facial stimuli were obtained from Hagiwara et al. (2012) with skin tone modifications made to them in Photoshop ${ }^{\circledR}$ for the purposes of this study. The facial stimuli consist of 14 White males and 16 Black males. The Black faces were manipulated to vary in Afrocentricity which consists of: skin tone, nose width, and lip size. There were 8 Black faces with high Afrocentricity (i.e., dark skin tone, wide nose, and large lips) and 8 Black faces with low Afrocentricity (light skin tone, narrow nose, and thin lips).

\section{Procedures}

Eye-tracking Task. After signing the informed consent document, participants were seated approximately 32 inches away from the Tobii X2-60 compact edition eye-tracking monitor (25" with a 16:9 aspect ratio). The researcher remained in the same room seated in front of the participant divided by a partition. The researcher controlled the presentation of the stimuli on the main computer.

Prior to the presentation of the stimuli, the researcher would start the Tobii eyecalibration process to ensure accurate eye-tracking. Once conditions were satisfactory, 
participants were instructed to read the information and instructions that was presented on the screen:

\section{Background Information}

"Your primary task is to select people to be part of a work group. Based on past research, we know that people can form highly effective work groups with only a brief exposure to a person. The work group you will form will face [a physical challenge requiring physical strength and agility/an intellectual challenge requiring strong verbal skill and excellent grammar]. When a set of faces is presented, look at the faces and use your best judgment to determine if the person has [strong physical strength and agility/verbal skill and excellent grammatical skill] necessary to contribute to the work group. We already know the [physical strength and agility/verbal and grammatical skill] of each person based on testing already done in our laboratory, and we want to know if you can form the best team possible with only minimal exposure to faces. That is, can you form a highly effective work group with only minimal information about a person? Please work as hard as you can to form the best work group possible."

\section{Instructions}

"You will be given a chance to see what the procedure will look like. First, there will be a prompt screen reminding you to select the person who you believe is best candidate for the work group. Next, you will be shown a slide with a "+" in the center of the screen. Please look at the "+". When that screen disappears you will be then shown two individuals for 5 seconds. Select the individual who you believe is best suited for the work group."

Trials begin with a prompt screen that either states: "The work group requires someone who is physically strong and agile (athletic condition). Which person would best join the group?" or "The work group requires someone who is articulate and intellectual. Which person would best join the group (verbal condition)?" Followed by the fixation slide (+ screen), which will last for 2 seconds. Participants are asked to direct their attention to the " + " in order to ensure that their gaze does not accidentally fall upon a face once the stimuli is presented. In addition this control, the position of the faces was also counterbalanced. After 5 seconds of 
stimuli exposure, there will be a prompt slide asking for them give their face choice. Upon receiving an answer and recording the response, the researcher will press the designated key on the keyboard to move onto the next stimuli. There are a total of 15 trials. Once the eye-tracking portion of the study has been completed, participants will then be instructed to move to a new room where they will be asked to perform the E-Prime trait rating task.

E-Prime Task. Participants were seated in front of a computer monitor and a keyboard for their use. Participants were asked to read the instructions on screen provided by the E-Prime program. The task required the participants to rate the same male faces presented during the eyetracking task.

\section{Dependent Measures}

There were three dependent measures. The first dependent measure was the selection of a face by the participants from the array of two faces on each of the 15 trials. The second dependent measure was the eye-gaze pattern recorded by the Tobii Eyetracker. Of the two faces in each array, visual attention to each of the faces was measured. There were five types of eyetracking data: Total Fixation Duration, Fixation Count, Total Visit Duration, Visit Count and Time to First Fixation.

All of the eye-tracking data types describe the nature of participants' fixations within an AOI or area of interest (programmed into the visual stimuli in the Tobii ${ }^{\circledR}$ eye-tracker). A fixation was defined as a pause of eye movement on a specific area of the visual field where both eyes were focused. Total Fixation Duration was the average time of all fixations on a given AOI. Fixation Count was the average number of fixations on an AOI. Total Visit Duration was

the average of all visits to an AOI. A visit was defined as the time interval from the first fixation on an AOI to the next fixation outside of the AOI. Visit Count was the average number of visits 
to an AOI. Time to First Fixation was the average time interval from when the stimulus appear on screen to the start of the first fixation on an AOI.

The third dependent measure was the trait rating response that participants gave for each face stimuli that was shown during the Eye-tracking task. The order of face presentation was randomized. Each trial consisted of a face image accompanied by a number rating scale beneath it ranging from 1-9 (Appendix A). Both sides of the scale had a trait each that were opposite to each other (for the full list please see Appendix B). The number would indicate which trait the participant perceived the person in the image to have ( 5 being neutral). There are a total of 30 faces for which the participants must give ratings for 9 trait dimensions (270 trials).

\section{Results}

\section{Visual Attention}

There were 5 types of visual behavior: fixation duration, fixation count, visit duration, visit count, and time to first fixation. Several of the types were combined to summarize the nature of the participants' visual behavior. Fixation count and visit count were combined into a "count" measure to describe the frequency of activity within a face AOI. Fixation duration and visit duration were combined into a "time" measure to describe the total length of time that was spent looking at a given face AOI. Time to first fixation was analyzed separately to indicate the interest in a particular face.

The repeated measure (i.e., the 15 trials during the eye-tracking phase) was analyzed in three separate analyses based on array type. The rationale for this arrangement was due to the qualitative difference in the paired facial stimuli (refer to Appendix B for examples). All Black Arrays (ABA) was composed of a High Afrocentric and a Low Afrocentric face. Mixed Arrays had a White face paired with either the High Afrocentric face (MA-H) or the Low Afrocentric face (MA-L).

\section{Fixation Count and Visit Count}


All Black Arrays. For the analyses of count constructs, a 2 (stereotype) x 5 (trials; for All Black Arrays or ABA) mix model ANOVA was used with a multilevel nested structure. Afrocentricity (High or Low) was nested within trials and count measures (i.e., 2; Fixation count and Visit count) were nested within Afrocentricity. There was no main effect of stereotypes on frequency of visual behavior for the ABAs, $F(1,58)=.030, p=.864, \eta_{p}^{2}=.001$. There was no main effect for Afrocentricity, $F(1,58)=.422, p=.518, \eta_{p}^{2}=.007$. There was also no stereotype by Afrocentricity interaction effect, $F(1,58)=.056, p=.814, \eta_{p}^{2}=.001$.

Mixed Arrays. A 2 (stereotype) x 2 (Afrocentricity) mix model ANOVA with a multilevel nested structure was used. Faces (3) were nested within level of Afrocentricism and within faces were the 2 AOI count measures.

The first analyses looked at the visual count differences of the High Afrocentric faces and White faces $(\mathrm{MA}-\mathrm{H})$. There was no stereotype main effect, $F(1,58)=.021, p=.886, \eta_{p}^{2}=.00$. There was a Afrocentricity main effect, $F(1,58)=28.016, p=.000, \eta_{p}^{2}=.326$. High Afrocentric faces $(M=5, S E=.165)$ received higher frequency of visual activity than White faces $(M=$ $4.214, S E=.161)$. There was no stereotype by Afrocentricity interaction, $F(1,58)=.02, p=.90$, $\eta_{p}^{2}=.00$

The second analyses looked at the differences between Low Afrocentric faces and White faces. There was no stereotype main effect, $F(1,58)=.14, p=.71, \eta_{p}^{2}=.002$. There was no Afrocentrcity main effect, $F(1,58)=.579, p=.45, \eta_{p}^{2}=.01$. There was no stereotype by Afrocentrcity interaction, $F(1,58)=.08, p=.78, \eta_{p}^{2}=.001$

The third analyses looked at their visual count differences of the High Afrocentric and Low Afrocentric faces (MA-L). There was no stereotype main effect, $F(1,58)=.015, p=.902$, $\eta_{p}^{2}=.00$. There was an Afrocentricity main effect, $F(1,58)=9.076, p=.004, \eta_{p}^{2}=0.135$. High Afrocentric faces $(M=5, S E=.165)$ were looked at more frequently than Low Afrocentric faces 
$(M=4.581, S E=.157)$. There was no stereotype by Afrocentricity interaction, $F(1,58)=.01, p$ $=.921, \eta_{p}^{2}=.00$

\section{Fixation Duration and Visit Duration}

All Black Arrays. For the analyses of time constructs, a 2 (stereotype) x 5 (ABA trials) mix model nested ANOVA was used with Afrocentricity nested within trials and time measures (fixation duration and visit duration) nested within Afrocentricity. There was no main effect of stereotypes on the amount of time participants spent in looking at the faces in the ABAs, $F(1,58)$ $=.178, p=.675, \eta_{p}^{2}=.003$. There was no main effect of Afrocentricity, $F(1,58)=.061, p=$ $.806, \eta_{p}^{2}=.001$. The was no Afrocentrcity by stereotype interaction, $F(1,58)=.143, p=.706$, $\eta_{p}^{2}=.002$

Mixed Arrays. A 2 (stereotype) x 2 (Afrocentricity) mix model ANOVA with a multilevel nested structure was used. Faces (3) were nested within level of Afrocentricism and within faces were the 2 AOI time measures.

The first analyses looked at the time differences between High Afrocentric faces with White faces $(\mathrm{MA}-\mathrm{H})$. There was no main effect of stereotypes, $F(1,58)=.06, p=.81, \eta_{p}^{2}=$ .001 . There was a Afrocentricity main effect, $F(1,58)=22.858, p=.00, \eta_{p}^{2}=.28$. High Afrocentric faces $(\mathrm{M}=1.787 \mathrm{~s}, \mathrm{SE}=.07)$ were looked at longer than the alternative White faces $(M=1.457, S E=.061)$. There was no stereotype by Afrocentricity interaction, $F(1,58)=.05, p$ $=.82, \eta_{p}^{2}=.001$

When comparing the time difference between Low Afrocentric faces with White faces (MA-L), there was no main effect of stereotypes, $F(1,58)=.90, p=.77, \eta_{p}^{2}=.001$. There was no Afrocentricity main effect, $F(1,58)=.15, p=.703, \eta_{p}^{2}=.003$. There was no stereotype by Afrocentricity interaction, $F(1,58)=1.07, p=.30, \eta_{p}^{2}=.018$ 
When comparing the duration of visual activity between the two different mixed array types, there was no main effect of stereotypes, $F(1,58)=.140, p=.710, \eta_{p}^{2}=.002$. There was a Afrocentricity main effect, $F(1,58)=10.536, p=.002, \eta_{p}^{2}=0.154$. Across both stereotype conditions, High Afrocentric faces with their white counterparts $(M=1.787 \mathrm{~s}, S E=.073)$ were viewed longer than Low Afrocentric faces $(M=1.597 s, S E=.66)$. There was no stereotype by Afrocentricity interaction, $F(1,58)=1.013, p=.318, \eta_{p}^{2}=.017$

\section{Time to First Fixation}

All Black Arrays. A 2 (stereotypes) x 5 (ABA trials) mix model nested ANOVA (Afrocentricity was nest within trials) was used for this analysis. There was no main effect of stereotype between conditions, $F(1,58)=.297, p=.588, \eta_{p}^{2}=.005$. There was a main effect of Afrocentricity, $F(1,58)=5.41, p=.024, \eta_{p}^{2}=0.084$. Across conditions, Low Afrocentric faces $(M=.69 \mathrm{~s}, S E=.055)$ were often viewed before High Afrocentric faces $(M=.79 \mathrm{~s}, S E=.069)$ when participants were simultaneously presented both faces. There was no stereotype by Afrocentricity interaction, $F(1,58)=.162, p=.689, \eta_{p}^{2}=.003$

Mixed Arrays. A 2 (stereotypes) x 2 (Afrocentricity) mix model ANOVA was used with faces (3) nested within Afrocentricity. First, initial visual attention was compared between the Black face and their partnered White faces (i.e., High Afrocentric faces with White faces and Low Afrocentric faces with White faces) to determine if the physical work group stereotype would cause initial attention to Black faces. Then comparison was made between High and Low Afrocentric Black faces to see if there was a preferential difference.

There was no main effect of stereotype for MA-H, $F(1,58)=0.00, \mathrm{p}=.984, \eta_{p}^{2}=.00$. There was no Afrocentricity main effect, $F(1,58)=2.276, p=.137, \eta_{p}^{2}=.038$. There was also no stereotype by Afrocentricity interaction, $F(1,58)=.584, p=.448, \eta_{p}^{2}=.010$. 
There was also no main effect of stereotype for MA-L, $F(1,58)=.763, p=.386, \eta_{p}^{2}=$ .013 . There was no Afrocentricity main effect, $F(1,58)=.275, p=.602, \eta_{p}^{2}=.005$. There was also no stereotype by Afrocentricity interaction, $F(1,58)=2.720, p=.105, \eta_{p}^{2}=.045$.

When comparing only time to first fixation of High and Low Afrocentric Black faces, there was still no main effect of stereotype, $F(1,58)=.016, p=.900, \eta_{p}^{2}=.00$. There was no Afrocentricity main effect, $F(1,58)=1.219, p=.274, \eta_{p}^{2}=.021$. There was also no stereotype by Afrocentricity interaction, $F(1,58)=.449, p=.506, \eta_{p}^{2}=.008$.

\section{Behavior}

Work Candidate Choices. In order to determine the bias in participants' choice of work candidates, responses were sorted into a frequency count for when the High Afrocentric face and Low Afrocentric face were selected for each type of work group. As previously stated, given the nature of the arrays, the analyses for bias was split into three different array types: ABA, MA-H, and MA-L.

For ABAs, a 2 (stereotype) x 2 (Afrocentricity choice: High vs. Low option) mix method ANOVA revealed that the two stereotype means were identical and did not differ from the grand mean. There was a choice main effect based on Afrocentricity, $F(1,58)=31.353, p=.00, \eta_{p}^{2}=$ .351. The Low Afrocentricity faces $(M=3.25, S E=.134)$ were picked more often than High Afrocentricity faces $(M=1.75, S E=.134)$. There was no stereotype by choice interaction, $F(1$, 58) $=2.617, p=.111, \eta_{p}^{2}=.043$.

For MA-H, the analysis revealed that the two stereotype means were identical and did not differ from the grand mean. There was no main effect of choice based on Afrocentricity, $F(1,58)$ $=.714, p=.402, \eta_{p}^{2}=.012$. There was no interaction effect, $F(1,58)=1.984, p=.164, \eta_{p}^{2}=$ .033 . 
For MA-L (relative to this particular array the High Afrocentricity face was the Low Afrocentric face due to having a greater degree of Afrocentric features when compared to the White), the 2 (stereotype) x 2 (Afrocentricity choice) mix model ANOVA revealed that the two stereotype means were identical and did not differ from the grand mean. There was a choice main effect based on Afrocentricity, $F(1,58)=8.394, p=005, \eta_{p}^{2}=.126$. Low Afrocentric faces $(M=1.833, S E=.115)$ were selected more frequently than the White faces as the best candidate the work group $(M=1.167, S E=.115)$. There was no stereotype by choice interaction, $F(1,58)$ $=.336, p=.565, \eta_{p}^{2}=.006$.

Trait Ratings. As previously mentioned, participants were also rated the thirty faces that appeared in the work group selection phase (i.e., eye-tracking) on 9 different trait measures. For the purposes of looking at racial stereotypes, only four questions were used in the rating analysis. Questions 1 and 2 assessed the participants' judgment of the targets' level of athleticism (e.g., Q1. "Physically Weak - Physically Strong”; Q2. "Physically Uncoordinated - Physically Agile) while questions 3 and 4 assessed verbal proficiency (e.g., Q3. "Verbally Unskilled - Verbally Skilled"; Q4. "Grammatically Skilled - Grammatically Unskilled”). The two sets of questions served as physical and verbal indicators of ability, respectively.

The analyses consisted of a 2 (stereotype) x 3 (Afrocentricity) mix model ANOVA. Nested within Afrocentricity were individual faces (8) and nested within faces were ability indicators (2). Physical and verbal indicators were separately analyzed.

For physical indicators, there was no stereotype main effect, $F(1,58)=.400, p=.530$, $\eta_{p}^{2}=.007$. There was an Afrocentricity main effect, $F(2,57)=48.364, p=.00, \eta_{p}^{2}=.631$. The relationship best fit a quadratic relationship, High Afrocentric faces $(M=6.688, S E=.127)$ and Low Afrocentric faces $(M=6.912, S E=.117)$ were rated higher (stronger) than those with White faces $(M=5.802, S E=.126)$. There was no stereotype by Afrocentricity interaction, $F(2,57)=$ $1.027, p=.365, \eta_{p}^{2}=.035$ 
For verbal indicators, there was no stereotype main effect, $F(1,58)=.081, p=.776, \eta_{p}^{2}=$ .001 . There was a Afrocentricity main effect, $F(2,57)=6.422, p=.003, \eta_{p}^{2}=.184$. In contrast to ratings on physical indicators, the scores were lower for High Afrocentric faces $(M=5.136, S E=$ $.123)$ and Low Afrocentric faces $(M=5.347, S E=.122)$ when compared to White faces $(M=$ $5.602, S E=.115)$. Finally, there was no stereotype by Afrocentricity interaction, $F(2,57)=$ $1.408, p=.253, \eta_{p}^{2}=.047$

\section{Discussion}

\section{Afrocentricity Bias}

Hypotheses 1 and 2 were not supported. The between-subjects stereotype manipulation failed to influence visual behavior and choice. Rather, it was the Afrocentricity manipulation (i.e., the degree of skin tone, nose width, and lip size) that drove the differences in visual attention and choice preferences depending on the array type of the stimuli. In terms of frequency and the duration of visual activity (i.e., number and duration of fixations and visits respectively), significant Afrocentricity bias was only present during High Afrocentric/White face mixed trials where High Afrocentric faces received more attention than White faces. There was no significant difference in bias between Low Afrocentric faces and White faces. Strangely, High Afrocentric and Low Afrocentric faces in the all Black arrays did not significantly differ in preferential visual attention as predicted by the racial phenotypicality bias (Maddox, 2004; Malloy et al., 2013).

In parallel, when looking at candidate choices, it is within the High Afrocentric/White face mixed arrays that showed no differences in preference (i.e., explicit behavior). One possible explanation was that participants were deliberately motivated to be egalitarian and avoided a biased response when they were faced with two highly contrasted individuals. However, in doing so, visual processing was much more focused on the High Afrocentric faces. Interestingly, excluding the aforementioned High Afrocentric/White face mixed arrays, participants were 
favorably selecting the Low Afrocentric faces as the primary candidate for both all Black arrays and Low Afrocentric/White face mixed arrays.

In terms of the failure to find any significant differences in visual attention and candidate choice between the physical and verbal ability primes, they may be not effective in race association activation as originally envisioned. First, given the context of the study in which participants must play the role of the employer, systematic selection of Black and White candidates still presents a situation where racial prejudice may occur. Participants' behavior may have been altered to counteract potential racial bias (Devine, 1989). Alternatively, one could also question the effectiveness of the two positive primes. Associations with race and verbal and physical ability may not be as strong as race and criminality. Or perhaps the two primes were overshadowed by the overall positive nature of the study. This may have been a contributing factor. Recall that for initial visual attention that for Time to First Fixation eye-tracking variable; there was a significant bias in looking at Low Afrocentric faces first when presented with two black candidates in both conditions.

Nonetheless, the present study still showed that racial bias can occur which manifested in their visual attention during one particular type of array (i.e., High Afrocentric/White). In addition, during the eye-tracking period, they had to also select the candidate. Depending on the visual and categorical saliency (Afrocentricity; degree of race membership) of the contrast between two faces, participants' choices were affected. In the High Afrocentric/Low Afrocentric face arrays, both faces were outgroup members; the natural inclination was to pick the Low Afrocentric face which, as explained by racial phenotypicality bias, was the face closest in similarly to the White in-group. As previously mentioned, with the overall positive nature of the study, this outcome would have been predicted by phenotype bias. In the Low Afrocentric/White face array, Low Afrocentric faces were selected most frequently as the candidate. According to phenotype bias, White candidates were expected. However, when we look at the preferred choice during High Afrocentric/White face arrays, there was no significant choice difference despite 
biased visual attention. The peculiar preference of Low Afrocentric faces over White faces may actually be explained by out-group positivity bias (Harber, Stafford, and Kennedy, 2010; ). For High Afrocentric/White face arrays, participants seem to take particular note of the Black and White contrast of the features of the candidates' face and in doing so influenced them to make choices that conform to the egalitarian ideal.

Participant's facial trait ratings further support the idea of outgroup positivity bias. Overall, Black faces had higher ratings for physical strength and agility than White faces (results partially support hypothesis 3 ). However, contrary to the prediction of racial phenotypicality bias, Low Afrocentric faces were rated higher in physical ability than High Afrocentric faces. High Afrocentric faces, being of the extreme end of the stereotypical phenotype, should have been rated the highest in physical ability. In terms of verbal ability, the findings more closely followed the predicted rating pattern according to the phenotypicality bias; white faces received the highest rating followed by Light Afrocentric face then High Afrocentric face (hypothesis 4).

\section{Out-Group Positivity Bias}

The current finding for these Low Afrocentric/White mix array may be explained by an out-group positivity bias. There are two possible sources of the bias. Malloy and Kinney (2014) showed that during reward allocation, high status members (arbitrarily made though a minimal group paradigm) will often select the out-group members to receive a beneficial outcome if they do not see them as threatening to their own economic resources. Within the context of the current study, particularly for Low Afrocentric/White arrays, Low Afrocentric candidates (low status) were favored. Falling within the specifications of Malloy and Kinney, the Black candidate should not have been perceived as a threat to their in-groups' well-being. Verbal ability ratings still showed that participants rated White faces as the most proficient. However, within the trait ratings for physical indicators, the scores for strength and agility for Light Afrocentric faces were significantly higher than White. Therefore, for those asked to select the candidate best suited for 
physical activity, one would expect Black candidates would be selected more often. However, that was not the case.

This inconsistency may suggest that the White participants are not selecting the out-group members based on perceived lack of threat of the out-group but rather perceived threat to an egalitarian self-identity. Harber et al. (2010), demonstrated this through a forced-choice survey that would threaten the White participants' egalitarian self-identity by asking leading questions pertaining to anti-minority outcomes. As controls, the other two manipulations would either reinforce their identity (pro-minority outcomes) or did not change it (shopping-related questions). Participants with the anti-minority surveys would evaluate reports supposedly written by a minority much more favorably (albeit superficially with a majority compliments rather than critiques) than White authored reports.

\section{Limitations}

Ultimately, participants may have used a multitude of various cognitive processes in order to prevent prejudice. Therefore it would be wise to know how to identify and fully understand their impact in the context of the current study. Research has shown that explicit control of implicit responses is possible (Walleart, Ward, \& Mann, 2010). Within the Implicit Association Task (IAT) paradigm the experimental group was told to avoid stereotyping were which in turn increased their accuracy. Interestingly, for the experimental group, response latency for incompatible trials also increased which suggested more cognitive resources were taxed.

The current study did not implement a way to record the response time of participants' answers during the eye-tracking phase and therefore missed the opportunity to have an objective measure for inhibition. In addition, administration of cognitive measures would also help reveal internal factors in producing implicit and explicit behavior. The cognitive processes of interest 
may include level of motivation to not be prejudice or type of motivation (i.e., internal, to maintain an egalitarian ideal or external, to not appear racist).

\section{Future Goals}

The aim of this line of research was to help determine the impact of automatic associations of Afrocentric features with their respective stereotype; which therefore helps us understand racism. Alternatively, the study also sought to causally link implicit racial bias to explicit racial bias. However, due to the nature of research on racism, accuracy of methodology is of great importance in order to avoid or account for extraneous variables. Future goals of this study will seek to incorporate a more comprehensive set of measures on internal process to account for inhibition of racial bias. The trait ratings proved to be a great asset in terms of providing further support to the presence of an out-group positivity bias. Finally, implementation of primes will be re-evaluated to produce stronger automatic associations. 


\section{Reference}

Blair, I. V., Judd, C. M., Sadler, M. S., \& Jenkins, C. (2002). The role of afrocentric features in person perception: Judging by features and categories. Journal of Personality and Social Psychology, 83, 5-25.

Blair, I. V., Judd, C. M., \& Chapleau, K. M. (2004a). The influence of Afrocentric facial features in criminal sentencing. Psychological Science, 15, 674-679.

Blair, I. V., Judd, C. M., \& Fallman, J. L. (2004b). The automaticity of race and Afrocentric facial features in social judgments. Journal of Personality and Social Psychology, 87(6), 763-778.

Devine, P. G. (1989). Stereotypes and prejudice: Their automatic and controlled components. Journal of Personality and Social Psychology, 56, 5-18.

Eberhardt, J. L., Goff, P. A., Purdie, V. J., \& Davies, P. G. (2004). Seeing black: Race, crime, and visual processing. Journal of Personality and Social Psychology, 8(6), 876-893.

Hagiwara, N., Kashy, D. A., \& Cesario, J. (2012). The independent effect of skin tone and facial features on Whites' affective reactions to Blacks. Journal of Experimental Social Psychology, 48, 892-898.

Harber, K. D., Safford, R., \& Kennedy, K. A. (2010). The positive feedback bias as a response to self-image threat. British Journal or Social Psychology, 49, 207-218.

Maddox, K. (2004). Perspectives on racial phenotypicality bias. Personality and Social Psychology Review, 8, 383-401.

Malloy, T. E., Chau, S., Bulevich, J., \& Maddox, K. (2013). Skin tone and crime stereotypes differentially affect whites' visual attention to Black faces: A basic mechanism in racial phenotype bias. Unpublished Manuscript, Rhode Island College. 
Malloy, T. E., \& Kinney, L. (2014). Benevolence and self-protection intergroup relations. Manuscript submitted for publication.

Maddox, K. B. \& Gray, S. A. (2002). Cognitive representations of black Americans: Reexploring the role of skin tone. Personality and Social Psychology Bulletin, 28, 250-259.

Ostrom, T. M., Carpenter, S. L., Sedikides, C., \& Li, F. (1993). Differential processing of ingroup and out-group information. Journal of Personality And Social Psychology, 64, 2134.

Wallaert, M., Ward, A. \& Mann, T. (2010). Explicit control of implicit responses: simple directives can alter IAT performances. Social Psychology, 41(3), 152-157.

Appendix A 


\section{Please rate the person:}

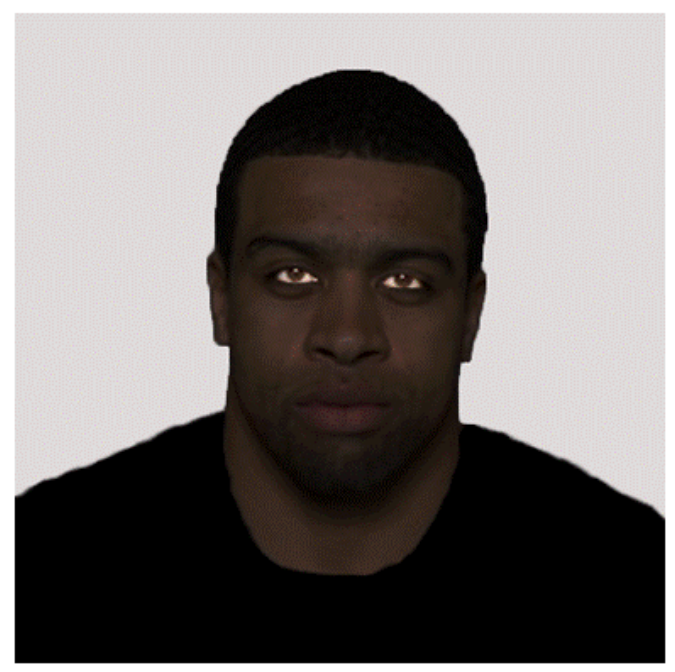

\begin{tabular}{c|llllllllll|}
$\begin{array}{c}\text { Physically } \\
\text { Strong }\end{array}$ & 1 & 2 & 3 & 4 & 5 & 6 & 7 & 8 & 9 & $\begin{array}{c}\text { Physically } \\
\text { Weak }\end{array}$ \\
\hline
\end{tabular}

Visual Stimuli for Trait Rating Task

Appendix B

Physically Strong - Physically Weak 
Physically Agile - Physically Uncoordinated

Verbally Skilled - Verbally Unskilled

Grammatically Skilled - Grammatically Unskilled

Outgoing - Shy

Agreeable - Disagreeable

Good Student - Bad Student

Happy - Unhappy

Cultured - Uncultured

Appendix C 


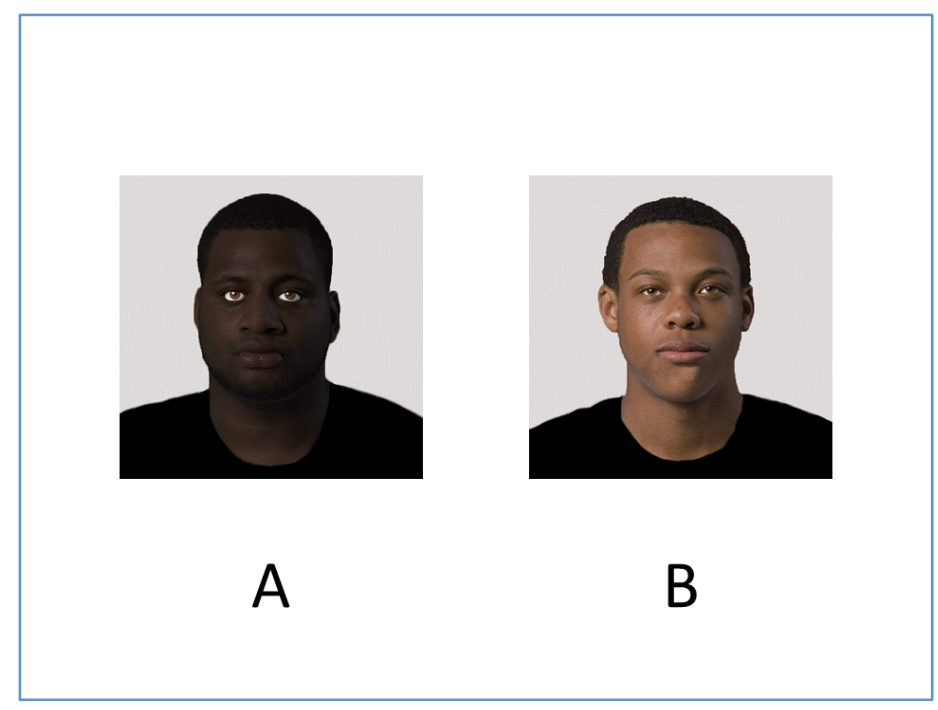

All Black Array

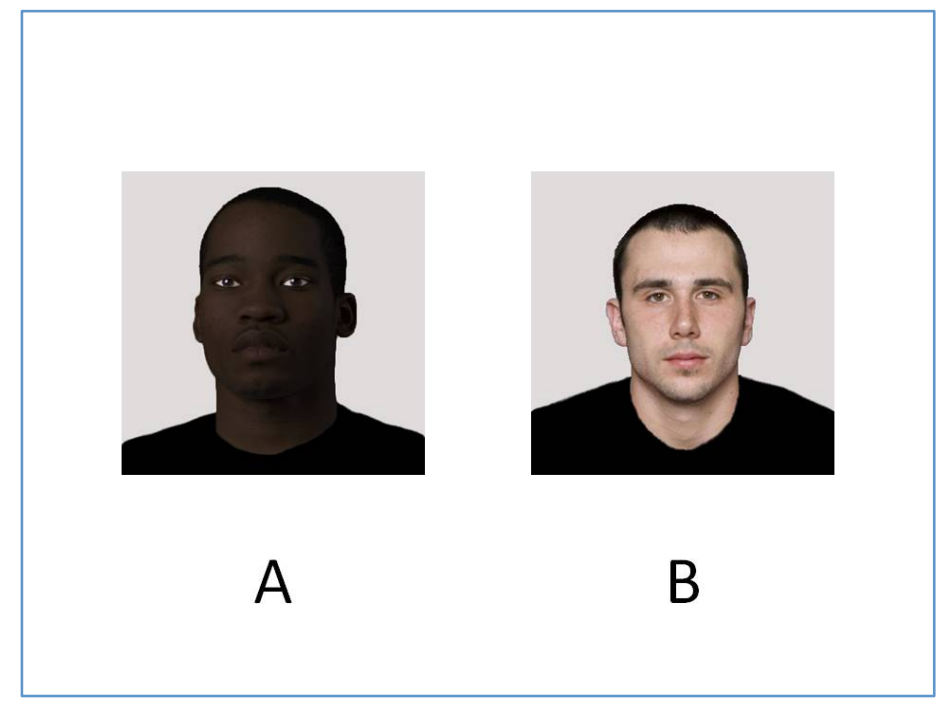

Mixed Array - High Afrocentricity 


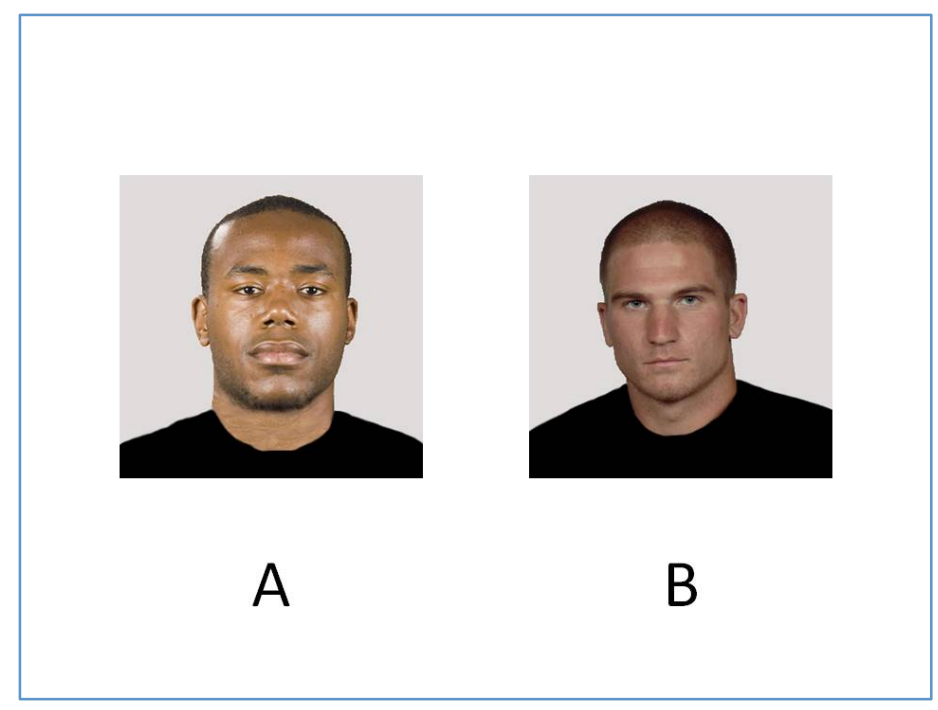

Mixed Array - Low Afrocentricity 